\title{
A cultura como viés de integração: Estudo de caso do movimento Fronteras Culturales na fronteira Brasil-Uruguai ${ }^{1}$
}

\author{
La cultura como viés de integración: Estudio de caso del movimiento \\ Fronteras Culturales en la frontera Brasil-Uruguay
}

\section{The culture like viés of integration: Study of case of the movement Cultural Borders in the border Brazil-Uruguay}

Bel. Bruno César Alves Marcelino²

\begin{abstract}
Resumo
O presente artigo propõe efetuar uma análise inicial sobre o processo de integração na fronteira sul do Brasil com o Uruguai, tomando como enfoque a integração cultural de base, atribuída à sociedade civil e aos seus processos socioculturais de integração. Como objeto de estudo, delimitou-se a análise das ações criadas no âmbito do movimento Fronteras Culturales. Será analisado a atuação tanto do Estado-Nação quanto da sociedade civil o os seus âmbitos de integração.
\end{abstract}

Palavras-chave: Fronteras Culturales; Integração Sociocultural; Fronteiras; Brasil e Uruguai.

\section{Resumen}

El presente artículo propone efectuar un análisis inicial sobre el proceso de integración en la frontera sur de Brasil con lo Uruguay, tomando como enfoque la integración cultural de base, atribuida a la sociedad civil y a sus procesos socioculturales de integración. Como objeto de estudio, se delimitó el análisis de las acciones creadas en el ámbito del movimiento Fronteras Culturales. Será analizado la actuación tanto del Estado-Nación cuánto de la sociedad civil el sus ámbitos de integración.

Palabras-clave: Fronteras Culturales; Integración Sociocultural; Fronteras; Brasil y Uruguay.

\begin{abstract}
The present article proposes to effect an initial analysis on the process of integration in the border south of Brazil with the Uruguay, taking like approach the cultural integration of base, attributed to the civil society and to his processes socioculturales of integration. Like object of study, delimited the analysis of the actions created in the field of the movement Cultural Borders. It will be analysed the performance so much of the State-Nation how much of the civil society the his fields of integration.
\end{abstract}

\footnotetext{
${ }^{1}$ Trabalho apresentado como artigo final da disciplina: Seminário Teórico: América Latina e as Integrações Regionais no Mestrado em Integração Contemporânea da América Latina - ICAL, Universidade Federal da Integração Latino-Americana - UNILA (2016).

${ }^{2}$ Bacharel em Produção e Política Cultural, mestrando em Integração Contemporânea da América Latina - PPG ICAL; Centro Latino-Americano de Estudos em Cultura - CLAEC e Universidade Federal da Integração LatinoAmericana - UNILA; Bolsista do Programa de Demanda Social da PRPPG - UNILA; Foz do Iguaçu, Paraná, Brasil; brunomarcelino@claec.org. Trabalho apresentado no I Seminário Latino-Americano de Estudos em Cultura - SEMLACult, Foz do Iguaçu/PR, Brasil, 2017.
} 
Keywords: Cultural borders; Integration Sociocultural; Borders; Brazil and Uruguay.

\section{Introdução}

A faixa de fronteira entre o Brasil e Uruguai se estende por um total de 985 quilômetros, desde a tríplice fronteira entre Brasil-Argentina-Uruguai na região oeste até o extremo sul do Brasil na foz do Arroio Chuí no município homônimo, englobando do lado brasileiro o estado do Rio Grande do Sul e do lado uruguaio os departamentos de Artigas, Rivera, Cerro Largo, Treinta y Tres e Rocha. Fazem fronteiras por terra ou via pontes internacionais os municípios de Santana do Livramento (Brasil - BR) e Rivera (Uruguai UY), Quaraí (BR) e Artigas (UY), Jaguarão (BR) e Rio Branco (UY), Barra do Quaraí (BR) e Bella Unión (UY), Chuí (BR) e Chuy (UY) e Aceguá (BR) e Aceguá (UY).

Buscaremos por meio de alguns referenciais teóricos, identificar e discursar criticamente os avanços e/ou retrocessos que ocorreram entre os municípios elencados acima, por meio da criação do movimento como ferramenta de fomento e promoção da integração cultural da região fronteiriça.

\section{A fronteira e a Integração Cultural}

De acordo com o geógrafo Otto Maull, os principais fins da fronteira são “distinguir o meu do teu; proteger o território nacional; isolá-lo, quando necessário, e facilitar-lhe o intercâmbio, quando conveniente" (apud MATTOS, 2011, p. 112).

Essa definição caracteriza a visão de fronteira presente na concepção institucional e oficial imposto pelos Estados-Nação, que na sua formação, impõe como objetivo principal da fronteira o de proteger seu território e a identidade nacional, impondo uma linha de separação, econômica, social e cultural com os demais Estados. Diferentemente da visão institucional do Estado, presenciamos nas relações de base em regiões de fronteiras, trânsitos culturais e sociais que perpassam os limites interpostos pelo maquinário político-jurídico-administrativo dos Estados-Nação.

Bento $(2015$, p.40) nos traz um conceito que trata a fronteira como "espaços físicos, geográficos, de distinção para a afirmação de identidades coletivas situadas nesses territórios específicos". Para ele "fronteiras são invenções culturais, territoriais, de comunidades antigas com territórios e identidades culturais diferentes". 
Ele também nos traz uma explanação sobre o fenômeno de integração cultural e social desenvolvido nessas regiões:

\begin{abstract}
Os sujeitos coletivos protagonistas dos processos de construção das experiências de integração regional de Estados são sujeitos localizados no vértice institucional de poder dos Estados e na base popular constitutiva de tais Estados. Porém, enquanto as experiências de integração de vértice podem ser caracterizadas pela transitoriedade dos eventos institucionais, e pela assinatura de acordos para a realização de projetos nem sempre executados, a integração de base é um dado permanente, fático, real, entre as populações das cidades integradas de fronteira (BENTO, 2015, p.46).
\end{abstract}

Bento (2015) enfatiza que a integração de base, que é advinda dos intercâmbios naturais causados pelo transito de pessoas residentes em ambas as regiões, são as verdadeiras ações concretas de integração cultural e social e não somente as ações propostas pelos governos, que na sua maioria, só reafirma o que já ocorre há anos de forma natural pela sociedade civil.

Segundo Mazzei (2012), a fronteira uruguaia com o Brasil representa 6,8\% do total de área de fronteira que o país possuí com os restantes países sul-americanos e que abarca um total de 798.478 habitantes residentes nas áreas fronteiriças, sendo que do lado uruguaio o departamento de Cerro Largo é o segundo maior em nível populacional representando $25.7 \%$ da população local. Para Mazzei (2012, p. 35):

Las ciudades fronterizas uruguayo-brasileñas pueden definirse como sociedades cuyos grupos sociales interactúan sostenidos por una convivencia que antepone a restricciones formales su libertad de circulación en la frontera. Serían escenarios en los cuales fluyen solidaridades, asistencias, lealtades, fraternidades, cooperaciones y negociaciones de todo tipo facilitadas por el respaldo directo o indirecto de la sociedad civil organizada a través de distintas representaciones en sus espacios públicos y privados.

Podemos verificar por meio deste trecho, que a região foco de nossos estudos, é uma localidade que vive um constante intercâmbio sociocultural, sendo a sociedade civil a principal responsável pela manutenção deste, independente de restrições ou legislações impostas pelos Estados-Nação aqui representados pelos governantes dos dois países. Este intercâmbio contínuo é o responsável pelo sentido da totalidade territorial desta fronteira, gerando a denominada integração fronteiriça de fato e não somente a integração fronteiriça de direito idealizada pelos instrumentos jurídicos e que na prática acaba sendo inviável de se efetivar.

O autor nos fala que essas sociedades têm em prática a "integração de fato" do que a “integração de direito", sendo o seu principal fator o potencial de interação, o imediatismo e a facilidade de intercâmbios, diferentemente do ocorrido com as legislações e acordos legais, 
"cuyas interacciones, ante la inmediatez y facilidad de intercambios beneficiosos que garantizados por confianzas mutuas generalmente eluden y desafían la cargas de los controles legales" (MAZZEI, 2012, p. 36).

A cultura é considerada por muitos autores como um importante campo na relação entre os Estados-Nação. Hugo Suppo e Mônica Lessa (2007, p. 223) nos dizem que a cultura, entendida como um sistema de valores simbólicos e sociais, constitui-se como um fator de grande influência na política externa dos Estados-Nação, servindo como ferramenta de aproximação da sociedade, bem como geradora de conflitos (apud CARVALHO; FILHO, 2011, p. 2). Alexander Wendt (1999, apud CARVALHO; FILHO, 2011, p. 3), entende a cultura como o principal atributo na formação da identidade nacional, sendo então, um fator relevante no comportamento dos Estados-Nação e consequentemente nos processos integracionistas da região.

Lessa (2010, p. 50) nos fala que:

\begin{abstract}
Nesse sentido, a idéia de que na "globalização", ou na "pós-modernidade", como prefere Jameson (200), a cultura não é mais uma "expressão relativamente autônoma da organização social" mas a "própria lógica" do capitalismo tardio aponta para a necessidade de se repensar o lugar da cultura a partir 1945, articulado com as expectativas, perspectivas e as disputas travadas em seu nome.
\end{abstract}

A partir da globalização e dos processos pós-modernos a cultura passa a ser vista como um mecanismo chave na manutenção do capitalismo e do Estado-Nação, ganhando espaço em seus meios de poder e consequentemente o reconhecimento dos processos culturais vivenciados pela sociedade civil no vértice do meio social.

Uma forma de verificação desse reconhecimento foi o aumento significativo de políticas públicas na área da cultura, Canclini (2005), considera as políticas culturais como intervenções realizadas pelo Estado, instituições civis e grupos comunitários organizados, com o intuito de promover o desenvolvimento simbólico, satisfazendo as necessidades culturais da população e a sua transformação social.

Ele ainda ressalta, que as políticas culturais não devem ser implementadas somente de forma local ou regional, mas devem garantir o intercâmbio e a globalização dos fluxos levando-se, em conta, o caráter transnacional dos processos simbólicos e materiais da atualidade, em um tempo onde as indústrias culturais atravessam fronteiras nos agrupando e conectando de forma globalizada. O autor considera a sociedade civil organizada e os grupos culturais, ferramentas essenciais para a promoção das políticas culturais, em conjunto com o 
Estado e com os grupos organizados, sendo esses os responsáveis pela expansão simbólica, social e cultural da população.

Nesse sentido Coelho (1997, p.293), no Dicionário Crítico de Política Cultural, conceitua políticas culturais como:

Constituindo (...) uma ciência da organização das estruturas culturais, a política cultural é entendida habitualmente como programa de intervenções realizadas pelo Estado, entidades privadas ou grupos comunitários com o objetivo de satisfazer as necessidades culturais da população e promover o desenvolvimento de suas representações simbólicas. Sob este entendimento imediato, a política cultural apresenta-se assim como o conjunto de iniciativas, tomadas por esses agentes, visando promover a produção, distribuição e o uso da cultura, a preservação e a divulgação do patrimônio histórico e o ordenamento do aparelho burocrático por elas responsável.

Dessa forma, Coelho (1997), assim como Canclini (2005) traz uma visão ampla sobre o que são e quem promovem essas políticas, podendo-se verificar nesses dois pensamentos que as políticas culturais são essenciais para a subsistência dos grupos sociais e também são as principais ferramentas de integração cultural. Elas são responsáveis não só por promover o novo, mas também, por preservar o que já está dado e a participação das sociedades civil nesse aspecto se faz essencial e altamente necessária, deixando as mesmas o papel que exercem como coadjuvantes para o de protagonistas.

Segundo Ribeiro (1989, p. 9, apud CARVALHO; FILHO, 2011, p. 3):

"Relações culturais são também as comunicações que" grupos sociais", as comunidades acadêmicas, os artistas, os produtores de cultura, espontaneamente, estabelecem entre si, independentemente de fronteiras, com ou sem ajuda estatal e, algumas vezes, até contra a vontade desses estados."

Verifica-se que a sociedade civil, apesar de estar sob a "guarda" dos Estados-Nação, mantem relações socioculturais espontâneas, que perpassam fronteiras físicas e que independem do Estado para acontecer, até mesmo em regiões de fronteira, que a princípio se demonstram como regiões conflituosas e de afirmação da identidade e do poderio nacional.

Nesta mesma linha de pensamento Sánchez (2011) afirma que as relações fronteiriças na América Latina, vão além das necessidades apontadas como principais pelos órgãos administrativos do Estados-Nação, para ele as relações são baseadas principalmente nos contextos históricos e culturais dos povos que habitam as fronteiras antes mesmo delas existirem como tais:

Cabe destacar además, que muchas de las comunidades que hoy habitan las fronteras latinoamericanas no se reconocen en las mismas, aunque se pretenda destacar lo contrario desde los centros de poder nacional. Por lo general, las fronteras son habitadas por comunidades asentadas en ellas históricamente y por tanto reconocibles de un extremo y del otro de la línea divisoria, lo que estas no reconocen 
es la línea que las separa administrativamente pero no afectiva y tradicionalmente. Muchas de estas comunidades regionales para el caso de la América continental son originarias e incluso hablan idiomas diferentes a los oficiales de sus estados nacionales, se identifican a sí mismas como entes individuales y cada vez menos reconocen al estado nación como soporte de salvaguarda de sus identidades (SÁNCHEZ, 2011, p. 3.3.5)

Com base nesses referenciais, iremos agora analisar a sua aplicação no caso específico do movimento Fronteras Culturales, considerando este como uma ferramenta criada para promover o diálogo e a integração entre a sociedade civil e os seus grupos sociais e culturais dos municípios da região de fronteira nos dois países.

\subsection{O Movimento Fronteras Culturales como instrumento de integração}

A análise do objeto foi centrada nos relatos trazidos por Ricardo Almeida (2010), no capítulo Calendário de Integração Cultural Brasil-Uruguai: Uma Experiência que integra o livro Fronteiras e Relações Brasil-Uruguai. O Fronteras Culturales, foi um movimento de base, teve início no mês de julho de 2010 quando um grupo de ativistas culturais com o apoio do Ministério da Cultura do Brasil se reuniram na cidade de Santana do Livramento/RS, com representantes de prefeituras e grupos culturais da região para iniciar uma agenda de atividades que pudessem promover o intercâmbio cultural e a organização de ações conjuntas, objetivando a troca de experiências e o intercambio sociocultural da região da fronteira entre o Brasil e o Uruguai.

O movimento teve grande participação no processo de alinhamento de políticas públicas na área da cultura, tanto pela União, quanto pelo Estado do Rio Grande do Sul e dos municípios da região fronteiriça, bem como na autonomia das organizações e da liberdade de participação social nos processos decisórios das políticas públicas, foi um movimento fundamental para orientar o processo de integração cultural da região.

Entre algumas ações desenvolvidas pelos integrantes do movimento, estão a elaboração de editais dos Pontos de Cultura $^{3}$ da fronteira, a capacitação de agentes culturais, a proposição de pautas nos acordos assinados entre os dois países, contemplando as singularidades da região. Outro ponto importante que cabe destacar é a participação do movimento na formulação de um grupo de trabalho entre os atores sociais e culturais da região, garantindo a comunicação e a sinergia entre todos os agentes envolvidos nos projetos

\footnotetext{
${ }^{3}$ A Política Nacional de Cultura Viva foi implementada a partir do ano de 2004 e institucionalizada por meio da Lei Federal no 13.018/2014 para garantir a ampliação do acesso da população aos meios de produção, circulação e fruição cultural a partir do Ministério da Cultura, e em parceria com governos estaduais e municipais e por outras instituições, como escolas e universidades.
} 
e ações desenvolvidos. Fruto desse grupo de trabalho, foi o estabelecimento de comissões binacionais em diversas localidades da fronteira, por meio da atuação em rede e constituindose em um movimento regional.

Dentre as ações pensadas pelo movimento a primeira a sair do papel foi a organização da Carta da Fronteira ${ }^{4}$, entregue no mesmo ano aos presidentes Luiz Inácio Lula da Silva e José Pepe Mujica, o documento apresenta diversos aspectos socioculturais da fronteira, segundo Ricardo Almeida (2015) a carta reconhece a histórica convivência entre ambos os povos da fronteira Brasil-Uruguai que produziu um patrimônio cultural com identidade própria e que a fronteira se constituiu em um corredor cultural no território do Bioma Pampa, com suas singularidades e diversidade ambiental e cultural. $\mathrm{O}$ documento ainda afirma que:

[...] a dimensão cultural é um dos eixos integradores para o desenvolvimento sustentável, pois visa a promoção da autoestima e do sentimento de pertencimento, o reconhecimento e valorização do patrimônio histórico e cultural das comunidades fronteiriças e que é importante e urgente fortalecer as ações culturais das comunidades da fronteira, bem como ampliar e democratizar o acesso aos serviços e bens materiais e imateriais, às políticas e ações culturais, e fortalecer a economia da cultura, as capacidades e os saberes locais (RIBEIRO, 2010, p. 01 apud ALMEIDA, 2015, p. 219).

A carta também estabelece uma agenda de atividades a serem desenvolvidas pelo movimento, entre elas podemos elencar: I - a constituição de uma comissão binacional, integrando o poder público e a sociedade civil dos municípios de fronteira; II - atribuir a essa comissão o dever de articular as ações promovendo a criação de espaços públicos para a formulação de políticas culturais para a região da fronteira; III - garantir no âmbito governamental do Brasil e do Uruguai o reconhecimento da comissão como um fórum legítimo de representação e de tomadas de decisões nas políticas culturais da região, e comprometer os ministérios e órgãos culturais competentes, com os propósitos listados na carta, por meio do firmamento de um protocolo de cooperação cultural; IV - criar um fórum permanente para discutir diretrizes de políticas culturais a serem aplicadas pelos governos de ambos os países; V - criar mecanismos de flexibilização dos trâmites burocráticos facilitando o intercâmbio e a integração cultural; VI - o estabelecimento de acordos visando o fomento à formação artístico-cultural através do intercambio de políticas públicas culturais já adotadas em ambos os países, como os Pontos de Cultura, as Fábricas Culturais, as escolas binacionais, entre outros.

\footnotetext{
4 Disponível no blog da Professora Dra. Maria de Fátima Bento Ribeiro pelo seguinte link: http://brfatima.blogspot.com.br/p/carta-da-fronteira.html.
} 
Verifica-se que o movimento traçou metas de importância para a promoção da integração cultural da região, bem como estabeleceu mecanismos de debate e de discussão de políticas culturais pelo viés de base, valorizando a participação social da população fronteiriça.

Um dos principais pontos de organização do movimento foi a realização da Conferência de Cultura de Fronteira e o Seminário de Integração Cultural Brasil-Uruguai, a primeira edição ocorreu nos dias 29 e 30 de agosto de 2010 no município de Jaguarão/RS, o objetivo dos eventos é a reflexão aberta com a população da região da fronteira sobre as políticas públicas culturais em desenvolvimento e as que serão implementadas, além de ser um fórum de debate sobre os objetivos político-cultural do movimento, buscando promover o diálogo acerca dos processos de integração cultural.

Durante a primeira edição foi lançado oficialmente o movimento Fronteras Culturales e deliberada a criação das comissões binacionais em todos os municípios fronteiriços e compostas por membros do poder público e da sociedade civil, tendo como principal objetivo a promoção de projetos regionais e a visibilidade dos processos iniciados em zonas de fronteiras, também foi deliberada a criação de uma coordenação geral unificada do movimento. Houve a realização de mais duas edições, sendo a última no ano de 2014.

Antecedido por reuniões temáticas realizadas no âmbito da Comissão Binacional Brasil-Uruguai, no dia 6 de novembro de 2010 em Montevidéu, com a participação dos ministros de cultura dos dois países, foi elaborada a Declaração de Montevidéu, onde ficou estabelecido o comprometimento governamental para a assinatura do Protocolo de Cooperação Cultural, objetivando uma visão compartilhada de cultura, reconhecendo as identidades locais e valorizando a diversidade cultural e as manifestações da cultura popular. Em 30 de maio de 2011, foi assinado pela presidenta do Brasil, Dilma Rousseff e pelo presidente do Uruguai, José Pepe Mujica, o Protocolo de Intenções entre o Ministério da Cultura do Brasil e da Educação e Cultura do Uruguai, visando o desenvolvimento de ações conjuntas na área da cultura.

O Protocolo reconhece todas as ações desenvolvidas na fronteira pelo movimento Fronteras Culturales que antecederam a assinatura do documento, valorizando os agentes culturais e sociais e seus processos de movimentação sociocultural na região. Pontua como necessidades, o desenvolvimento de ações de cooperação, intercâmbio e divulgação mútua de experiências e manifestações culturais; a cooperação e o intercâmbio de políticas públicas, 
planos nacionais e programas culturais; promoção de ações voltadas para o fortalecimento das atividades culturais em ambos os países, considerando a diversidade cultural, étnica e linguística, entre outros pontos. Houve também o comprometimento da continuidade das reuniões bilaterais, por meio da implementação de grupos de trabalho responsáveis por sistematizar os processos existente na fronteira.

A assinatura do Protocolo é um claro reflexo do processo de reconhecimento da cultura como um ponto principal na integração entre os Estados-Nação sul-americanos, conforme demostra a realização no ano de 1992 da primeira Reunião de Secretários de Cultura e Autoridades Culturais do Mercosul, onde a cultura foi reconhecida como ferramenta central para o desenvolvimento econômico dos Estados (LESSA, 2010).

Também fruto do movimento e um dos objetivos propostos pela Carta da Fronteira, o Calendário da Integração Cultural Brasil-Uruguai foi discutido e aprovado no dia 16 de abril de 2013 no grupo de trabalho sobre educação e cultura dentro do movimento Fronteras Culturales, tendo posteriormente sua aprovação em uma reunião do Comitê de Fronteira.

O Comitê de Fronteira é um órgão criado com o objetivo de propor políticas públicas de promoção da integração fronteiriça e é composto por representantes do poder público e da sociedade civil organizada de ambos os países, na reunião de aprovação do calendário estavam presentes além dos representantes dos municípios fronteiriços, representantes do Ministério da Educação e Cultura do Uruguai, da Assessoria de Cooperação e Relações Internacionais e da Secretaria de Planejamento, Gestão e Participação Cidadã do Estado do Rio Grande do Sul, membros dos consulados do Brasil e do Uruguai atuantes na região, da Unipampa, da UFPel, da Universidade da República do Uruguai além de representantes de organizações da sociedade civil dos municípios da região.

Foram definidos quatro critérios que devem nortear as escolhas dos eventos: 1) os eventos devem simbolizar a integração entre os dois países; 2) que promovessem a geração de trabalho e renda na região; 3) que houvesse a participação tanto de brasileiros como de uruguaios em sua organização e 4) que fossem eventos que carregassem o reconhecimento da sociedade da sua região.

No dia 14 de março de 2014, após discussões internas no âmbito do Comitê de Fronteira e dos movimentos sociais que compuseram a comissão binacional de seleção, que foi a responsável por definir quais eventos seriam incluídos na primeira edição, foi lançado o 
Calendário de Integração Cultural Brasil-Uruguai ${ }^{5}$ 2014, durante o II Encontro de Cidades de Faixa de Fronteira RS, evento organizado pela Frente Nacional de Prefeitos.

Foram selecionados para esta primeira edição os seguintes eventos:

Março - Carnaval Internacional, em Quaraí-Artigas, Livramento-Rivera, Jaguarão-Río Branco e Santa Vitória do Palmar-Chuy.

Abril - Festival Internacional de Pandorgas, em Livramento-Rivera e Semana da Integração Cultural em Santa Vitória do Palmar-Chuy.

Maio - Seminário de Integração Cultural: Protocolo de Intenções Culturais. Brasil Uruguai, em Jaguarão e Río Branco.

Julho - Festival Internacional de Música no Pampa, em Bagé.

Agosto - Festival Binacional de Gastronomia e Mostra Binacional de Teatro em Livramento-Rivera.

Setembro - Semana da Integração da Cultura Gaúcha/Gaucha, em Livramento-Rivera e Aceguá-Aceguá.

Outubro - Exposição Feira Agropecuária, em Bagé.

Novembro - Festa Internacional do Churrasco e Festival Internacional de Cinema na Fronteira em Bagé e a Feira Binacional do Livro, em Livramento e Rivera.

Dezembro - Festival Internacional de Balonismo, em Aceguá-Aceguá.

Os eventos selecionados, por meio de parceria e auxílios em diferentes modalidades, contam com o apoio da Secretaria de Estado da Cultura do Rio Grande do Sul, do Ministério da Cultura do Brasil, do Ministério da Educação e Cultura do Uruguai, dos Centros MEC do Uruguai, das prefeituras, empresas privadas e organizações da sociedade civil que compõe a região da fronteira sul.

\section{Considerações finais}

\footnotetext{
${ }^{5}$ Maiores informações sobre o Calendário de Integração Cultural Brasil-Uruguai e do Comitê de Fronteira estão disponíveis na página oficial do projeto na rede social Facebook: Em português (Integração Cultural BrasilUruguai) em espanhol (Integración Cultural Uruguay-Brasil).
} 
Conforme as concepções utilizadas pelo geógrafo Otto Maull e trazidas por Mattos (2011), as ações oriundas do movimento Fronteras Culturales e que agora fazem parte de políticas públicas estatais, caracteriza a mudança recente dos Estados-Nação, que passaram a reconhecer as formas de integração de base das regiões de fronteira, por ser - de certa forma conveniente e vantajoso para a manutenção das suas relações, auxiliando no fortalecimento da integração regional entre os países fronteiriços. Isso só foi possível, levando em conta que a integração foi considerada uma saída para o crescimento da economia dos países sulamericanos, contra os efeitos eminentes da globalização (LESSA, 2010)

O papel do Estado-Nação será sempre o de fomentar a unidade entre os povos que o compõe, como uma nação de identidade única, sob a argumentação de que para fortalecer o Estado, deve-se ter uma identificação única na sociedade, pois ao se fragmentar a sociedade em grupos étnicos, culturais e sociais acabará ocorrendo rupturas na identidade nacional, provocando desequilíbrios na cultura política liberal adotada pelos Estados-Nação (HERNÁNDEZ SÁNCHEZ, 2011).

O que vai na contramão do que ocorre na base da sociedade, a região foco da pesquisa é historicamente uma localidade que possuí um grande fluxo social, por conta da sua localização fronteiriça, que causa uma forte movimentação sociocultural entre as regiões, onde culturalmente não há o reconhecimento por parte da sociedade civil, da fronteira física imposta pelo Estado-Nação.

Conforme Sánchez (2011) as sociedades oriundas das regiões fronteiriças muitas vezes não reconhecem as linhas divisórias estabelecidas pelos Estados-Nação com o intuito de estabelecer um limite de identidade cultural e social de seu território e respectivamente de seu povo, as ações emanadas dos projetos desenvolvidos pelos movimentos sociais da região da fronteira vão nesse sentido, utilizam como vetor principal o não reconhecimento da faixa de fronteira, considerando o território como único, dividindo costumes, relações sociais e culturais, festividades, laços familiares entre outros pontos de encontros socioculturais.

Como podemos verificar, a sociedade civil foi a grande precursora de todas as ações recentes de integração cultural na fronteira do Brasil com o Uruguai e que posteriormente foram reconhecidas e institucionalizadas pelos seus governos. Ainda assim, o Estado-Nação não reconhece ao todo a complexidade social e cultural presente na região, promovendo muitas vezes, políticas públicas que não contemplam às suas especificidades e não dialogam 
com as recorrentes transformações e transmutações advindas dos seus atributos históricos, geográficos, econômicos, políticos e sociais (MARCELINO, 2015).

Por outro lado, considerando as abordagens trazidas por Semprini (1999) sobre multiculturalismo, com base nas observações obtidas com a análise do objeto, pode-se dizer que os grupos e movimentos sociais ali presentes por meio da sua produção cultural e social, podem ser caracterizados como espaços multiculturais, pois exalam as diferenças culturais e sociais de seus atores, porém coexistem e defendem as suas especificidades, o que é de difícil alcance para o Estado, por falta de interesse, ocorre de maneira natural e em grande parte pacifica no dia-a-dia da sociedade civil e dos grupos socioculturais presentes na fronteira.

Este trabalho em complementação com uma pesquisa anteriormente executada denominada de "Cartografia da Cultura Fronteiriça", demonstram-se como ferramentas de análise da participação da sociedade civil na promoção das políticas de integração cultural e social na região, conforme segue:

Compreendendo que a área cultural necessita de uma política pública eficaz e que atenda as especificidades desse campo, e entendendo também que antes de qualquer ação na área cultural se faz necessário um prévio panorama da situação das instituições, coletivos e espaços culturais, o mapeamento realizado pelo projeto Cartografia da Cultura Fronteiriça é uma importante ferramenta de subsídio para a atuação dos governos em suas três instâncias e da sociedade civil articulada. Fez se necessário conhecer os grupos, entidades, aparelhos e agentes culturais que atuam nas cenas locais dos municípios de Arroio Grande e Jaguarão, afim de integrar as informações destes espaços através de uma rede atualizada (MARCELINO; MARCELINO; SANTANA, 2015, p. 266)

O movimento Fronteras Culturales demonstrou-se como uma exitosa ferramenta de promoção da integração cultural na fronteira sul do Brasil e norte do Uruguai, pois conforme o anteriormente exposto, as ações desenvolvidas no âmbito do movimento, como o Seminário de Integração Cultural Brasil-Uruguai, o Calendário de Integração Cultural Brasil-Uruguai, o Protocolo de Cooperação Cultural entre outros, promoveram o reconhecimento da fronteira em questão, como um dos principais centros de integração de base cultural no Mercado Comum do Sul (Mercosul) (ALMEIDA, 2015). Contando hoje com o apoio direto de vários organismos públicos de importância nacional e internacional como os Ministérios da Cultura de ambos os países e do próprio Mercosul, o que de fato agrega valor simbólico sobre a importância das ações desenvolvidas no âmbito dos movimentos sociais.

Cabe ressaltar que, o reconhecimento pelos Estados-Nação dos processos culturais de integração, por meio da promoção de políticas públicas culturais e sociais que fomentem a integração de base, é oriundo de temáticas acordadas anteriormente no âmbito das discussões 
sobre o Mercosul, conforme demonstra Lessa (2010, p. 53) em referência ao resultado do Encontro de Fortaleza realizado em 1996:

\begin{abstract}
Pensar integração regional do ponto de vista social e cultural, buscando incrementar a troca de experiências políticas e intelectuais, tendo como propósito o exame da possibilidade de criar-se uma rede institucional que contribua para a ampliação do nosso intercâmbio, não só como produtores de bens e serviços, mas também como sócios culturais que compartilham um conjunto de valores comuns. [...] Nossa reunião, portanto, deseja pensar a região e o Mercosul, para além de seu conteúdo econômico (Funag, 1997, p. 15)
\end{abstract}

A principal crítica a se fazer é, até que ponto a participação massiva do Estado na execução das ações que anteriormente eram feitas naturalmente pela sociedade civil, tornamse positivas no sentido do protagonismo social da sociedade civil que os promoviam, correndo o risco de se perder o principal ponto das ações que é a integração cultural de base e tornando o numa ferramenta de integração cultural de direito, com todas as mazelas e percalços do maquinário político-jurídico-administrativo do Estado-Nação.

\title{
Referências
}

ALMEIDA, R. Calendário de Integração Cultural Brasil-Uruguai. In: Fronteiras e relações Brasil-Uruguai. Org: MALLMANN, M. I. e MARQUES, T. C. S. Porto Alegre: EDIPUCRS, 2015. Disponível em: http://ebooks.pucrs.br/edipucrs/Ebooks/Pdf/978-85-397-0691-4.pdf. Acesso em 20 de junho de 2016.

BENTO, F. R. O papel das cidades-gêmeas de fronteira na integração regional SulAmericana. Revista Conjuntura Austral, Vol. 6, nº 27 - 28, p. 40-53, Dez. 2014/Mar. 2015. Disponível em: http://seer.ufrgs.br/index.php/ConjunturaAustral/article/view/51125. Acesso em 20 de junho de 2016.

BRASIL. Protocolo de Intenções entre o Ministério da Cultura da República Federativa do Brasil e o Ministério da Educação e Cultura da República Oriental do Uruguai para o desenvolvimento de ações conjuntas no âmbito da cultura. Disponível em: http://www.itamaraty.gov.br/pt-BR/component/tags/tag/177-uruguai. Acesso em 12 de julho de 2016. 
CANCLINI, N. Definiciones en transición. In: MATO, D. (Org). Cultura, política y sociedade: perspectivas latinoamericanas. Argentina: CLACSO, Consejo Latinoamericano de Ciencias Sociales. 2005.

CARVALHO, B. T; GOIANA FILHO, J. E. A. O papel da cultura nos processos de integração regional: o caso da UNILA. In: $3^{\circ}$ Encontro Nacional ABRI 2001, 2011, São Paulo. Disponível em:

http://www.proceedings.scielo.br/scielo.php?script=sci_arttext\&pid=MSC0000000122011000 100033\&lng=en\&nrm=abn. Acesso em 12 de julho de 2016.

COELHO, T. Dicionário crítico de política cultural: cultura e imaginário. São Paulo: Iluminuras, 2004.

\section{HERNÁNDEZ SÁNCHEZ, L. E. Concepciones Acerca de la Región en la Problemática} Actual de la Integración Latinoamericana. Villa Clara. 2011. Tese de Doutorado - Facultad de Ciencias Sociales - Universidad Central "Marta Abreu” de Las Villas. Disponível em: http://www.eumed.net/tesis-doctorales/2013/lehs/index.htm. Acesso em 22 de junho de 2016.

IPHAN. Declaração de Montevidéu. Disponível em:

http://portal.iphan.gov.br/uploads/legislacao/Legislacao_Declaracao_de_Montevideu.pdf. Acesso em 12 de julho de 2016.

LESSA, M. L. Mercosul Cultural: desafios e perspectivas de uma política cultural. Mural Internacionao, Ano 01, nº. 02, p. 50 - 58, 2010. Disponível em: http://www.epublicacoes.uerj.br/index.php/muralinternacional/article/view/5322/3923. Acesso em 12 de julho de 2016.

MARCELINO, B. C. A; MARCELINO, I. M. L; SANTANA, R. B. J. Cartografia da Cultura Fronteiriça: A Sociedade Civil e a Promoção das Políticas Culturais. Revista Conexões Culturais, Vol. 01, nº. 02, p. 260 - 267, 2015. Disponível em: http://periodicos.claec.org/index.php/cc/article/view/180. Acesso em 20 de junho de 2016.

MATTOS, C. M. Geopolítica - Vol.01. Rio de janeiro: Editora FGV, 2011. 
MAZZEI, E. Fronteras que nos unen, límites que nos separan. Montevideo: Imprenta CBA, 2012. Disponível em:

http://www.cci.edu.uy/sites/default/files/Mazzei,\%20E.\%20(2013).\%20Fronteras\%20que\%20 nos\%20unen\%20y\%201\%C3\%ADmites\%20que\%20nos\%20separan.\%20Montevideo\%3A\%2 OImprenta\%20CBA.pdf. Acesso em 20 de junho de 2016.

SEMPRINI, A. Espaço Público e Espaço Multicultural. In: Multiculturalismo. São Paulo: Edusc, 1999. 